\title{
Common Preposition Errors Committed by Iranian Students
}

\author{
Samaneh Yousefi \\ Department of English Language and Literature, Larestan Branch \\ Islamic Azad University, Larestan, Iran \\ Email: samaneh.yousefi91@yahoo.com \\ Afshin Soori (Corresponding author) \\ Department of English Language and Literature, Larestan Branch \\ Islamic Azad University, Larestan, Iran \\ Email: Afshin_soori@yahoo.com \\ Abusaied Janfaza \\ Department of Foreign Languages, Bandar Abbas Branch \\ Islamic Azad University, Bandar Abbas Iran \\ E-mail: s_janfaza@hotmail.com
}

Received: 10-08-2013

Accepted: 06-01-2014

Published: 01-05-2014

doi:10.7575/aiac.ijalel.v.3n.3p.1

URL: http://dx.doi.org/10.7575/aiac.ijalel.v.3n.3p.1

\begin{abstract}
This paper examined some common problems involving prepositions in learning a second language. Many students learning English as a foreign language commonly commit mistakes in prepositions. The aim of this paper is to survey the causes of errors in the use of prepositions that are frequently made by Iranian students. A diagnostic test (35 Multiple choice item) was constructed to test the students proficiency in using these prepositions. The prepositions selected for this purpose were; to, in, at, on, with, of, from, for, about, during, into under, over and by. This test was given to a group of 35 intermediate students. The results indicated that the errors committed by the students were due to both Inter-lingual and Intra-lingual interferences. It is hoped that this research will help teachers of English Language to be aware of these problems and re-evaluate their teaching approach.
\end{abstract}

Keywords: prepositions, errors, Inter-lingual and Intra-lingual interference, diagnostic test, common problems.

\section{Introduction}

Contrastive analysis is the systematic study of a pair of languages with a view to identifying their structural differences and similarities between the first language and the target language based on the assumptions that: the similarities facilitate learning while differences cause problems. Contrastive analysis theory pioneered by Fries assumed that these errors are caused by the different elements between the native language and the target language (Fisiak, 1981: 7).

Contrastive Analysis was used extensively in the field of second language acquisition (SLA) in the 1960s and early 1970s, as a method of explaining why some features of a target language were more difficult to acquire than others. According to the behaviorist theories prevailing at the time, language learning was a question of habit formation, and this could be reinforced or impeded by existing habits. Therefore, the difficulty in mastering certain structures in a second language (L2) depended on the difference between the learners' mother language (L1) and the language they were trying to learn.

There are two main types of error analysis: interlingual and intralingual (Richards and Sampson1980). Interlingual errors are those which are due to first language interference. Intralingual errors, on the other hand, are those which reflect the operation of learning strategies that are universal (Ellis and Barkhuizen 2009).

The theoretical foundations for what became known as the Contrastive Analysis Hypothesis were formulated in Lado'sLinguistics Across Cultures (1957). In this book, Lado claimed that those elements which are similar to [the learner's] native language will be simple for him, and those elements that are different will be difficult".

\section{Criticism}

In its strongest formulation, the Contrastive Analysis Hypothesis claimed that all the errors made in learning the L2 could be attributed to 'interference' by the L1. However, this claim could not be sustained by empirical evidence that was accumulated in the mid- and late 1970s. It was soon pointed out that many errors predicted by Contrastive Analysis were unaccountably not observed in learners' language. Even more confusingly, some identical errors were made by learners irrespective of their L1.It thus became clear that Contrastive Analysis could not predict all learning difficulties, but was certainly useful in the retrospective explanation of errors(Rustipa, S. 2011). 


\section{Literature Review}

Error Analysis on English as a foreign language (EFL) of Francophone Students:Ntumngia (1974) conducted research on error analysis at Illinois University at Carbondale. It was an applied linguistics study of the interlanguage of Francophone Cameroonian secondary school students. The aim of this study was to diagnose and analyze the errors of these students with the hope that this identification and analysis would result in implications for instructional strategies used by teachers of English. The result of the study indicated that the errorscommitted by the students were due to both interlingual and intralingual factors. The researcher was then able to make suggestions to foreign language teachers which pointed to the fact that if a positive attitude is taken towards errors, they can be beneficially utilize to facilitate the process of language learning.

Henning (1978) at the University of California analyzed developmental error patterns in adult Iranian learners of English as a foreign language. The subjects of this study were 22 Iranian women in the second semester of their first (freshman) year at Damavand College, Tehran, Iran. They participated in the experiment for course credit. These subjects had received an average of six years of previous EFL instruction, and were currently enrolled in an intensive program of twenty hours per week of classroom instruction with English as both subject and medium ofinstruction.(Mahmoodzadeh, 2012)

Delshad (1980) conducted a contrastive study of English and Persian prepositions andfound that Iranian EFL/ESL students have difficulty in the use of English prepositions. According to Delshad, Iranian EFL learners apparently tend to misuse or omit English prepositions (as cited in Jafarpour\&Koosha, 2006). Likewise, in an endeavor to determine the extent to which Iranian EFL learners' knowledge of collocation of prepositions is affected by their L1, Jafarpour and Koosha (2006) conducted a study in which the errors of the collocations of prepositions turned to yield the significance of Iranian EFL learners' L1 transfer. That is, Iranian EFL learners tend to carry over their L1 collocation prepositions to their L2 production.

According to Larsen, et.al the goals of Contrastive Analysis can be stated as follows: "to make foreign language teaching more effective, to find out the differences between the first language and the target language" (Larsen, et. al., 1992: 60).

In recent years, studies of foreign language acquisition have tended to focus on learner's errors since they allow for prediction of the difficulties involved in acquiring a foreign language. In this way, teachers can be made aware of the difficult areas to be faced by their students and devote special care and emphasis to them. Prepositions, on which the present study focuses, are one of these difficult areas. Thus the main purpose is to investigate the causes of errors in the use of English prepositions that are frequently made by Iranian students. There was a signification difference between errors made by the students due to mother tongue interference (MTI) and those made due to other learning problems (OLP). More errors were attributable to interference from Persian than to other learning problems. The term 'interlanguage' was firstly used by Reinecke in 1935 . He always used 'interlanguage' to refer to a nonstandard variety of a first or second language, used as a means of inter group communication. An interlanguage is developed by a learner of a second language who has not become fully proficient yet but is approximating the target language: preserving some features of their first language, or over generalizing target language rules in speaking or writing the target language and creating innovations. Language learners cannot correct their errors until they have sufficient knowledge. These errors occur in the course of the learner's study because they have not acquired enough knowledge. Once they acquire additional knowledge, they will be able to correct their errors and the more errors the learners correct the more conscious of language they will become.

But why do students still find difficulties in learning English when their teachers do their best to help them to achieve good results? The answer to this question is the fact that learning English or any other foreign language is difficult, not only for the Iranian students mentioned in this study, but for all students who want to learn a second language. Acceptance of this fact has led in recent years to a great deal of research on adult foreign language learning in general and errors in particular. Therefore, in other words, the occurrence of errors during the L2 learning process may not only be due to the pressure of the patterns of the mother tongue but also to imperfect learning of the new L2 patterns. But unfortunately most of the EFL teachers are not familiar with the common errors made by their students. Even if they are, however, it is not enough to be familiar just with the types of students' errors so as to arrive at the correct blend of good teaching, preventive teaching and remedial teaching. Teachers need to know, too, the causes of these errors. In this way, they should devote special care and emphasis in their teaching in order to overcome, or to avoid these predicted difficulties. For these reasons, research is necessary and error analysis is the best tool for describing and explaining errors made by speakers of foreign languages (Johanson, 1975).

The errors that learners of EFL are expected to make are due to several different causes. The one as noted above is caused by interference from the native language and the other is caused by interference from other structures in the target language. The first type of error occurs when a learner of a second language carries over the habits of his mother -tongue into the second language. This interlingual interference means that his L1 habits (patterns, systems or rules) interfere or prevent the learner, to some extent, from acquiring the patterns and rules of the second language (Corder, 1971). The second type of error is due to the interference of the L2 itself. This is termed intralingual interference. Some of the errors that are made by learners of an L2 are caused by the structure of the target language. Here, we are concerned only with prepositional errors and a limited number of prepositions. 
Preposition usage is one of the most difficult aspects of English grammar for non-native speakers to master. According to Celce-Murcia and Larsen-Freeman (1999), prepositions are generally troublesome to learners for whom English is a foreign or second language (p. 401). Takahaski (1996) also believes that the correct usage of prepositions is the greatest problem for EFL learners of English. Although the majority of Persian EFL learners have a good knowledge of English grammar and vocabulary; but, they seem to have serious problems with prepositions. It seemed reasonable to conduct a study to discover the types and the rate of grammatical errors on using prepositions, and to indicting the prepositional error types which disappear developmentally across different levels of language proficiency, and those which persist in the interlanguage of Persian EFL learners (Jalali,andShojaei, 2012)

Richards (1974) classified errors also, according to their causes, into two categories. The two categories are as follows:

1. Interlingual errors: these errors are caused by mother tongue interference.

2. Intralingual and developmental errors: this kind of errors occurs during the learning process of the second language at a stage when the learners have not really acquired the knowledge. In addition, errors are also caused by the difficulty or the problem of language itself.

English language teachers and researchers are well aware that English prepositional usage is one of the most difficult areas for students of EFL (Khampang, 1974: p. 215). "Prepositions are an ever- lasting problem for foreign learners of English “ (Mukattash, 1976: p. 269). English prepositions are difficult for any EFL learner because he/she usually relates them to his /her own MT (Mother tongue) prepositional system. Verbs and other parts of speech play a great role in the omission, addition and selection of a wrong preposition in English, which may affect the whole meaning of the idea intended by the learner. The main problem for these learners lies in the fact that not every Persian preposition has a definite equivalent in English and vice versa. For example, the Persian preposition "dær" - is used as an equivalent of "in, into, at, on, during, within, inside" and also the zero equivalent (?) in English. Another problem is that Iranian learners use or omit certain English prepositions according to Persian usage. So, by literal translation, we notice that when the Persian context requires a preposition (or requires none), learners make wrong responses accordingly, as illustrated in the following examples:

The boy enjoyed the film. The literal translation of this sentence is:

The boy enjoyed from the film.

In Persian, it is necessary to insert a preposition to make a relationship between the enjoyment and the film, which was the cause of that enjoyment. Without such a preposition the Persian sentence will have no sense. Therefore Iranian learners are likely to insert unnecessary prepositions when they express themselves in English. On the other hand, they may omit necessary prepositions as illustrated by the following example:

1. I must stay at the university (for) eight years.

The other type of errors that occurs with Iranian learners as well as with any other group of other EFL students, whatever their mother tongue -is caused by the interference of English itself. Note the following examples:

1. I came back at home. (Ø)ब

2. I visited toNeyavaran Palace. (Ø)

3. I like to listen at music. (to)

These examples are not cases of L1 interference, because their literal translation into Persian does not lead to these incorrect responses. They, therefore, fall into the second category of error: Intralingual errors. The present study was designed to diagnose and investigate the most common errors in the use of English prepositions.

\section{Research Questions}

The study aims at answering the following questions:

1. What are the most common errors in prepositions that are committed by the students?

2. What types of errors in use of prepositions (omission of prepositions, redundant or wrong use of prepositions) are more likely to be made by Iranian EFL learners?

3. Why do the students commit those errors?

\section{Methodology}

\subsection{Participants}

The subjects of this study were 35 Iranian EFL students. They were all male pre-intermediate students in a high school in Shiraz, Fars province in Iran. These participants were chosen based on the results of a proficiency test that was conducted to determine the level of students. They had completed their high school education, and their mother tongue, Persian, was the medium of instruction for their schooling. The students had already studied some English as a foreign language. Interference from Persian was most visible in the student's use of preposition.

\subsection{The Diagnostic Test:}

The purpose of this test was to reveal the most common errors made by the subject in the use of English prepositions. It was designed as a multiple choice test. So, the stem of the test item consisted for example of: "I fear__ him." And the

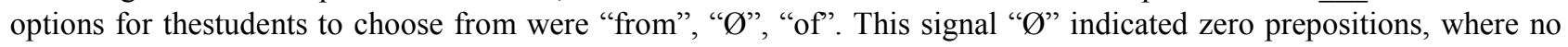


preposition should be inserted in the sentence. The prepositions on which the test was constructed and which were considered options for the test items were "in, at, to, with, on, for, from, of, by, about, during, into under and over". 37 multiple choice items were designed.The tests were gathered from several essay and dissertations.

\section{Results and Discussion}

As noted above, the purpose of this study is to discover what types of errors in use of prepositions (omission, redundant or wrong use) are more or less likely to be committed by Iranian EFL learners. In this respect, Table 1 below shows that the subjects under study have made errors related to wrong use of prepositions more frequently as compared with errors related to the omission or addition use of prepositions in L2.

Table1. Common errors in the use of English preposition due to MTI and OLP Interferences

\begin{tabular}{|c|c|c|c|}
\hline prepositions & Type of Error & $\begin{array}{l}\text { Percentage of errors due to } \\
\text { mother tongue interference }\end{array}$ & $\begin{array}{l}\text { Percentage of errors } \\
\text { due to other } \\
\text { learning problem }\end{array}$ \\
\hline \multirow{3}{*}{ Time } & a. Wrong use & $74.3 \%$ & $25.7 \%$ \\
\hline & b. omission & $13.1 \%$ & - \\
\hline & c. addition & $68.6 \%$ & $31.4 \%$ \\
\hline \multirow{3}{*}{ Space } & a. Wrong use & $71.4 \%$ & $28.6 \%$ \\
\hline & b. omission & $15 \%$ & - \\
\hline & c. addition & $37.9 \%$ & $62.1 \%$ \\
\hline \multirow{3}{*}{ Miscellaneous } & a. Wrong use & $35.3 \%$ & $64.7 \%$ \\
\hline & b. omission & $71.9 \%$ & $28.1 \%$ \\
\hline & c. addition & $47 \%$ & $53 \%$ \\
\hline TOTAL & a. Wrong use & Total percentage of MTI & $\begin{array}{l}\text { Total } \\
\text { percentage of } \\
\text { OLP }\end{array}$ \\
\hline \multirow{3}{*}{ TOTAL } & & $60.3 \%$ & $39.7 \%$ \\
\hline & b. omission & $33.3 \%$ & $28.1 \%$ \\
\hline & c. addition & $51.1 \%$ & $48.8 \%$ \\
\hline \multicolumn{2}{|c|}{ GRAND TOTAL } & $48.2 \%$ & $38.8 \%$ \\
\hline
\end{tabular}

Table 1indicated that wrong use of errors ( incorrect selection of prepositions) caused by MTI were the most frequent with $60.3 \%$ and omission errors (omission of necessary Prepositions) with $33.3 \%$ and addition errors (addition of unnecessary Prepositions) is $51.1 \%$. Errors caused by OLP in substitution errors are $39.7 \% .28 .1 \%$ and $48.8 \%$ of errors related to deletion and redundancy respectively are due to OLP also. Generally $48.2 \%$ of errors are due to the MTI and $38.8 \%$ of errors are due to the OLP.

(1) wrong use: An incorrect preposition is substituted for a correct one. For example:

- I apologize* from him. (Instead of to)

- He was angry *from his bad marks (instead of at).

(2) Addition: A preposition is used in a sentence which does not require a preposition. For example:

- He entered *into the room (an unnecessary into).

- They always discuss *about politics (an unnecessary about).

- Every person should use *from her real friends' advices (unnecessary from)

(3) Omission: A preposition is deleted which is necessary. For example:

- $\quad$ She came *Ø Sunday (omission of on).

- The classes are held * $\varnothing$ noon (omission of at)

\section{Wrong use}

This error type was made when the learners did not apply a correct preposition after a noun. 


\section{Addition}

This error type was made when the learners used an unnecessary preposition after a noun.

\section{Omission}

In this error category, the learners did not recognize that a preposition was required after the noun, thus omitting it. The main findings of this study were:

1. The choice of the wrong prepositions caused by MT interference.

2. In some other cases it was due to the absence of the preposition in L1 and the misapplication of rules in L2.

These errors were defined and then classified and sub -divided as follows:

\section{Prepositions related to "Time":}
1. a. Omission
1. b. Addition
1. c. Wrong use

2. Prepositions related to "Space":

2. a. Omission

2. b. Addition

2. c. Wrong use

3. "Miscellaneous" prepositions that includeprepositions used after nouns, verbs and adjectives:

3. a. Omission

3. b. Addition

3. c. Wrong use

Defining and classifying the errors:

\section{Prepositions denoting Time:}

These errors were all caused by interference from Persian. The prepositions included in this category are "in", “on", "at", "during" and "for".

1. wrong use: (errors caused by the selection of a wrong preposition)

a. Ininsteadofon, at:

1) Spring begins in the first of March. (on)

The boldface preposition is incorrect response given by the students and the preposition between brackets is the (correct response) of the reconstructed sentence in English.

2) In Friday I went to Shiraz.(on)

3) I was very happy in my holiday. (on)

4) In the end of the Journey we bought fruit. (at)

5) In the beginning of the holiday I went to Shiraz. (at)

6) In my last holiday I went to visit my sister. (on)

7) I go to school in seven o'clock. (at).

b. At instead of on, in , during:

1) Spring begins at the first of March. (on)

2) At the second day I went to the cinema. (on)

3) My aunt told us a story at the evening. (in)

4) At my last holiday I did many different things. (during)

the wrong use of " in " and "at" in all the above examples is caused by the interference of the Persian preposition "dar" , which is realized by more than one preposition in English to denote time.

2. omission (of a required preposition):

a. Ø instead of for

1-I must stay at the university $\boldsymbol{\varnothing}$ eight years. (for)

3. addition (addition of unnecessary preposition):

1. a. I enjoyed in the holiday. (Ø)

1. b. I enjoyed at the holiday. (Ø) 
Since "in" and "at" are both equivalents to the Persian "dær". One of the two is unnecessarily inserted due to interference.

\section{Prepositions denoting Space: made due to interference from Persian:}

The prepositions that were included under this category are" into", "on", "under", "at", "over", "to", "in" and "by".

They were sub-grouped as follows:

1. wrong use: (incorrect selection)

a. Into, on, under, at, over, to instead of in :

1) The plane is flying into the sky. (in)

2) I sleep on bed. (in)

3) We sat under the sunshine. (in)

4) I am at the third preparatory class. (in)

5) The boy sat over the armchair. (in)

6) When we arrived to Shiraz we bought fruit. (in)

Interference of Persian" be", which is equivalent to "to" and is used in the literal translation of this sentence, has led to the incorrect choice.

b. In, on instead of at:

1) I help my father in work. (at)

2) We sat on the table to eat lunch. (at)

The literal translation of both examples has led to the use in the one of "in work" instead of "at work "because these prepositions are equivalent to " dar" and in the other of "on the table", instead of " at the table" is because of interference from Persian "roye".

c. At, in instead of on:

1) I help my father in the farm. (on)

2) I help $m$ y father at the farm. (on)

3) I saw a football match in the TV (on)

4) I saw a football match at the TV (on)

7) We went to Shiraz in the bus. (on)

8) We went to Shiraz at the bus. (on)

2-omission of a required preposition:

1) When we arrivedØ Shiraz we bought fruit. (in)

2) We went $\boldsymbol{\varnothing}$ a Journey to the north of Shiraz.(on)

3) In spring people go $\varnothing$ picnics. (on)

4) It is interesting to go $\boldsymbol{\varnothing}$ a trip. (on)

The omission of "in" and "on" in all the above examples is attributable to MT interference.

3. Addition of a preposition which is not necessary in a sentence.

a.Toinstead of $\varnothing$ :

1) I came back to home. ( Ø)

2) I went to home happily. ( Ø)

4. Errors with Miscellaneous Prepositions

1. wrong use (choosing the incorrect preposition)

a. With instead of to, in, of:

1) I shall help people and be kind with them. (to)

2) We were interested with it. (in)

3) I like to pick roses with many colors. (of)

In English we say "kind to" people "interested in" something; also something "of many colors" to indicate the appropriate relationship, but literal translation cause these errors.

b. from instead of of:

1) I shall cure the man from diseases. (Of)

2. Addition of a preposition that is not required in an English pattern. 
1) People go to work with merrily. ( Ø)

2) We enjoyed from the film. (Ø)

The misuse of prepositions in all these examples is Attributable to MT interference.

In the following example, the errors were caused by imperfect learning of English patterns.

The prepositions that were included under this category are "for", "about", on, "in" and "during". They were classified as follows:

1. wrong use (incorrect selection)

For, about instead of on, in, during:

1) Spring begins for the first of March. (on)

2) I was happy for my holiday.(on)

3) I worked with my brother for my last holiday. (on)

4) My aunt told us a story for the evening. (in)

5) We were excited for the journey. (during)

6) I played with my sister about the holiday. (during)

Here, the wrong use of prepositions cannot be attributed to MT interference. In sentences 2,4,5 and 6, the wrong use of "for" and "about" instead of "on", "in" and "during" is related to the students' unawareness of L2 patterns, i.e. application of English patterns to contexts where they do not be relevant.

\section{Errors with Prepositions denoting Space which is the cause of imperfect learning:}

This section includes the following prepositions:

"at", "to", "in", "of" and "for", sub -grouped as before:

Wrong use:

a. At instead of to:

1) People go on journeys at the Dead Sea. (to)

2) I was pleased to come at school. (to)

"At" is used in both these examples due to false application of L2 patterns.

b. To instead of at, in:

1) The driver stopped to the petrol pump. (at)

2) I prayed to Al Aqsa Mosque. (at)

3) Her mother carried a basket to her hand. (in)

4) I spent my last holiday to Amman. (in)

c. On instead of in, at, of:

1) Some people go to their offices on their cars. (in)

2) I preyed on Al Aqsa Mosque. (at)

3) Some people are sitting at the side on the street. (of)

The use of "on" in the first two examples is related to false application of L2 patterns. The "car" is an enclosed space, so "in" is the appropriate preposition to use in the first example. "At" is to be used in the second example because we can pray at any point in or near the mosque. In the third example, the learners did not realize that here "of" is used as a part of the complex preposition "at the side of "which indicates that the side of the street is a part of the street. Instead, the two were use separately and the prepositions proper to each phrase given. This is again a case of false application of English patterns.

b. At instead of $\varnothing$

1) I came back at home. ( Ø)

2) I went at home happily. ( Ø)

In these two examples, the use of "at" is related to over-generalization. The subjects have "borrowed" the well remembered noun phrase "at home", learned in one context and applied it incorrectly to other contexts.

\section{Errors with Miscellaneous Prepositions:}

Miscellaneous prepositions are which denoting neither time nor space. They are usually followed or preceded by noun phrases or verb phrases, but also by adverbs or adjectives. The prepositions included under this category are "in", "of", "to", "for", "at", "after", "with", "of", "from" and "about". They were grouped and sub -grouped as follows:

1. wrong use:

a. In, of instead of to, for : 
1) I shall help people and be kind of them. (to)

2) The girl paid of the ice-cream. (for)

3) I want to be a soldier to fight in my country. (for)

The wrong use of the preposition "of" in the first example is related to overgeneralization; an analogy was made between "kind of" which means "sort of", and, "kind to" meaning "considerate'. In the second sentence "for" should be used to indicate exchange. In the third sentence it should be used to indicate purpose (i.e. for the sake of). The wrong use of the prepositions in the last two examples is, therefore, because of false application of English patterns.

\section{2. omission:}

\section{$\varnothing$ instead of with:}

I live $\boldsymbol{\emptyset}$ my father and mother. (with)

The deletion of "with" in this example has only one reasonable explanation: that the learners have misread "live" as "love" which may be related to the problem Persian speakers have in noticing English short vowels, since they are used to reading Persian where only consonants and long vowels are written.

\section{Addition:}

With, instead of $\varnothing$ :

1) My brother married withParvin. (Ø)

This sentence is result of literal translation or MT interference.

\section{Conclusion}

Based on this research the prepositions "in", "at" and "to" cause the most frequent errors.It was found that the errors made by the subjects were caused by two main factors: interference from Farsi and other learning problems. Significantly more errors were made due to interference from Farsi than due to other learning problems. This is because students find more difficulty in learning English patterns that are similar to, but in some way different from patterns of their own language than they do with learning patterns that are completely different.

The key to this problem is the fact that students always resort to literal translation before they form English patterns. In other words, they translate the English into Farsi and then the Farsi back into English, word for word (not phrase by phrase). So, errors made by them due to persian interference occur more frequently than those made by them due to other learning problems.

It is hopes that this piece of research will help teachers of English language who apply the sameEnglish program to reconsider the English textbooks and their teaching methods. Teachers need to be well conscious of these consequences in order to prepare appropriate exercises and help students to avoid further repetition of these problems. In so doing, teachers can teach English preposition from the beginning of their teaching. Teacher should teach their students that there is no one to one correspondence between English and Persian preposition. So, it is not enough just to teach preposition to them, teacher should raise student's awareness of the most common errors made by student.

\section{References}

Connor, U. M. (1996), Contrastive Rhetoric: Cross-cultural aspects of second-language writing. Cambridge, UK: Cambridge University Press.

Corder, S. P. (1971).Idiosyncratic dialects and error analysis. International Review of Applied Linguistics, 9, 147-159.

Celce-Murcia, M., \& Larsen-Freeman, D. (1999).The grammar book: An ESL/EFL teacher's course (2nd ed.). Boston: Heinle.

Delshad, S. (1980). Persian and English prepositions compared and contrasted from a pedagogical point of view. Unpublished Doctoral Dissertation. University of Texas, USA.

Ellis, R. (1994). The Study of Second Language Acquisition Oxford: Oxford University Press. ISBN 0-19-437189-1

Ellis, R. and Barkhuizen,G. ( 2009) Analysing Learner Language. Oxford: Oxford university press.

Fallah, M. (1991).Contrastive Linguistics and Analysis of Errors. Tehran. Iran University Press.

Henning, G. H. (1978). A developmental analysis of errors of adult Iranian students of English as a foreign language.Language Learning, 28, 387- 397.

JOHANSON, S. (1975). "The Uses of Error Analysis and Contrastive Analysis I. "English Language Teaching, 29(3), 246- 253.

Jallili, H. \& Shojaei, M. (2012).Persian EFL Students' Developmental versus Fossilized Prepositional Errors.Iran University.

Koosha, M. \& Jafarpour, A. A. (2006). Data-driven Learning and Teaching Collocation of Prepositions: The Case of Iranian EFL Adult Learners. Asian EFL Journal, 8(4), 192-209.

KHAMPANG, P.(1974). "Thai Difficulties in Using English Prepositions. Language Learning, 24, 2, 215-222. 
Lado, R. (1957). Linguistics across cultures: Applied linguistics for language teachers. University of Michigan Press: Ann Arbor.

MUKATTASH, L. (1976). A Pilot Project In Common Grammatical Errors in Jordanian English. Amman: The University of Jordan.

NTUMNGIA, F.Z. (1974). "Error Analysis: An Applied Linguistic Study of the Interlanguage of Francophone Cameroonian Secondary School Students." Ph.D. dissertation abstract, Illinois University.

Richards, J. C. (1974). Error analysis: Perspective on second language acquisition. London, UK: Longman.

Richards,J., \& Sampson,G.(1980) The study of learner English. In RichardsC.Jack(ed.), Error Analysis. London: Longman, 3-18.

Rustipa, S. (2011). Contrastive Analysis, Error Analysis, Interlanguage and the Implication to Language Teaching.Ragam Jurnal Pengembangan Humaniora, 11(1).

Zeinab, A. H. (1982). Common Errors in the Use of English Prepositions. Birzeit University. 